\title{
Simulation of performance of circular CFST columns under short-time and long-time load
}

\author{
Glib Vatulia ${ }^{1 *}$, Alexey Lobiak ${ }^{1}$, and Yevhen Orel $^{1}$ \\ ${ }^{1}$ Ukrainian State University of Railway Transport, Structural Mechanics and Hydraulics Department, \\ Feuerbach sq., 7, Kharkiv, 61050, Ukraine
}

\begin{abstract}
The method of calculation of concrete-filled steel tubular (CFST) columns with consideration of physical nonlinearity of materials, geometric nonlinearity of the confinement and the effect of the gain in strength of the core is considered. The method uses a step iteration algorithm, which involves analytical dependencies and the ultimate element simulation method. Allowance for creep of concrete is based on using the generalized kinetic long-term deformation curve and phenomenological deformation development equations. Creep of concrete is controlled through new structural factors that determine the structure of cement rock layers between sand and mortar grains between chip grains. The method is validated by comparing experimental results and theoretical data. The suggested method allowed to study the stress-strain and limit state of circular concrete-filled steel tubular columns, as well as to evaluate their effectiveness with account for the time factor.
\end{abstract}

\section{Problem statement}

Today, many analytical calculation methods for compressed concrete pipe elements give quite close values of bearing capacity [1]. Both general approach to the calculation of concrete structures with rigid or confinement reinforcement and such methods as bringing concrete to steel, numerical calculation methods based on the nonlinear deformation model, as well as approaches recommended by Eurocode 4 are applicable for steel concrete [2]. In general, the existing methods of taking into account the rheological properties of the concrete core involve complicated calculations and considerable error. Despite the wide choice, elaboration of a fully functional technique to calculate the stress-strain state under short-term and long-term loads, taking into account the deformation diagrams of the concrete core under conditions of volumetric stress, contact interaction between the confinement and the core and the geometric nonlinearity has not been completed yet.

\section{Calculation for short-term loads}

\subsection{Theoretical principles}

\footnotetext{
* Corresponding author: glebvatulya@gmail.com
} 
The set task is proposed to be solved based on the nonlinear model taking into consideration the specifics of core and confinement deformation under non-homogeneous stress. The main problem in calculation of the pipe concrete under such conditions is absence of core deformation diagrams $\sigma_{\mathrm{c} 3}-\varepsilon_{\mathrm{c} 3}$, the appearance of which will be determined by the value of the lateral pressure of the steel concrete on the concrete $\sigma_{\mathrm{cr}}$ which is unknown in advance (Fig. 1).
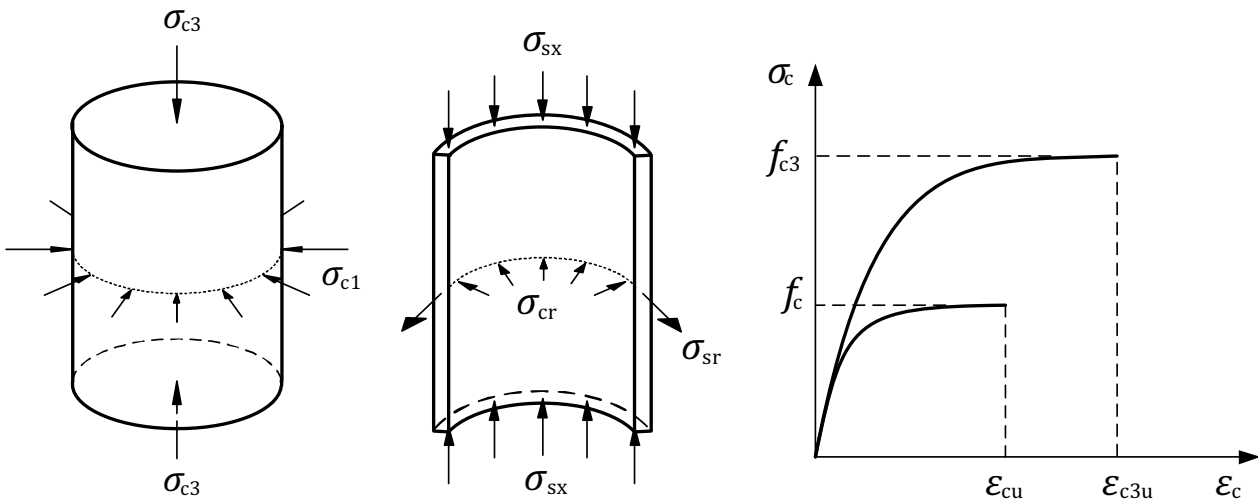

Fig. 1. Stressed state of the concrete core and steel confinement reinforcement.

In view of the state-of-the-art computer technologies, this solution can be implemented mathematically using a computer complex as the main simulation instrument [3]. The suggested calculation method uses a step-iteration algorithm. It is accepted at the first iteration of the first load, step lateral pressure $\sigma_{\mathrm{cr}}=0$ and the strength of the core is determined exclusively by the axial compression strength of the cylinder $f_{\mathrm{cc}}$. Further, iteration search for actual core strength values $f_{\mathrm{c} 3}$ in accordance with Karpenko criterion [4] under triaxial compression of the element is performed:

$$
f_{\mathrm{c} 3}=f_{\mathrm{cc}}+k \sigma_{\mathrm{cr}}
$$

Lateral pressure ratio $k$ is determined depending on the relative edging level $m=\sigma_{\mathrm{c} 1} / \sigma_{\mathrm{c} 3}$ :

$$
k=1 /(0.1+0.9 m) .
$$

The last iteration will determine the actual components of the stress-strain state of the first load step: axial $\sigma_{\mathrm{c} 3}$ and transverse $\sigma_{\mathrm{c} 1}$ stresses in the concrete, principal compressive $\sigma_{\mathrm{sx}}$ and radial $\sigma_{\mathrm{sr}}$ stresses in the confinement, as well as respective relative deformations $\varepsilon_{\mathrm{c} 3}, \varepsilon_{\mathrm{c} 1}, \varepsilon_{\mathrm{sx}}, \varepsilon_{\mathrm{sr}}$. Consequently, the second and further load steps are calculated up to the exhaust of the carrying capacity. It is thus assumed that the limit state for pressure with little eccentricities occurs when one of three conditions is fulfilled: either the strength of the concrete core $\sigma_{\mathrm{c} 3}=f_{\mathrm{c} 3}$, or of the confinement $\sigma_{\mathrm{sr}}=f_{\mathrm{y}}$ is exhausted or as a result of reaching ultimate deformations $\varepsilon_{\mathrm{c} 3}=\varepsilon_{\mathrm{cu}}$.

The ultimate element model for calculation of the stress-strain state consists of two blocs (the confinement and the concrete core) united into combined action using unilateral connection accepting compression and shear (Fig. 2, a).

The confinement is simulated taking into account physical and geometrical nonlinearity, while the core material is given by variable deformation laws. Load is transferred through an auxiliary part providing distribution of forces along the loading plane. The triangulation circuits were obtained as a result of solving a separate problem of finding a compromise between time and accuracy of calculation. 


\subsection{Calculation data}

The method was validated by comparing the calculation data with the experimental data. The adopted concrete pipe elements were $500 \mathrm{~mm}$ long, with diameter $102 \mathrm{~mm}$, confinement wall thickness $3 \mathrm{~mm}$, and the core made of concrete with prism strength $16 \mathrm{MPa}$. Load transfer is accepted for the combined cross-section, i.e. simultaneously to the concrete and the pipe.

The results for the ultimate condition were visualized on the stress fields which are shown separately for the confinement (Fig. 2, a, b) and the core (Fig. 2, d, e).

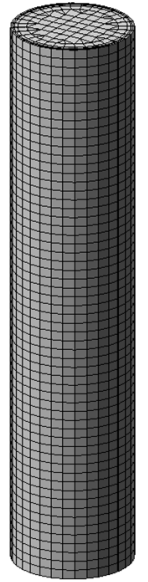

a)

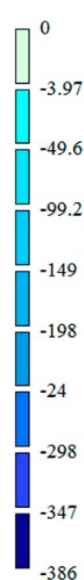

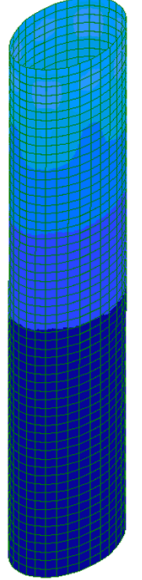

b)

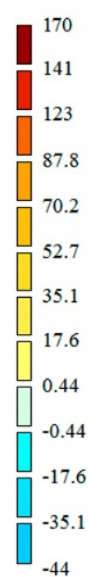

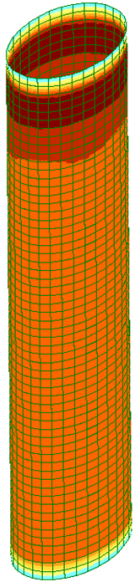

c)

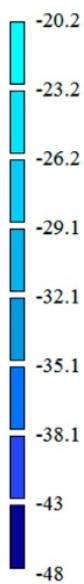

$-48$

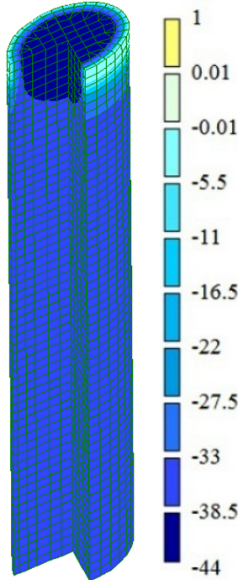

d)

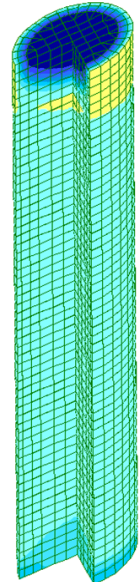

e)

Fig. 2. Stress state of the concrete pipe element ( $\mathrm{a}-$ general view of the model, $\mathrm{b}$ and $\mathrm{c}-$ stresses in the confinement $\sigma_{\mathrm{sx}}$ and $\sigma_{\mathrm{sr}}, \mathrm{d}$ and $\mathrm{e}-$ stresses in the core $\sigma_{\mathrm{c} 3}$ and $\left.\sigma_{\mathrm{c} 1}\right)$.

The calculation data were analyzed for dependencies of stress changes (Fig. 3, a) and deformations (Fig. 4).

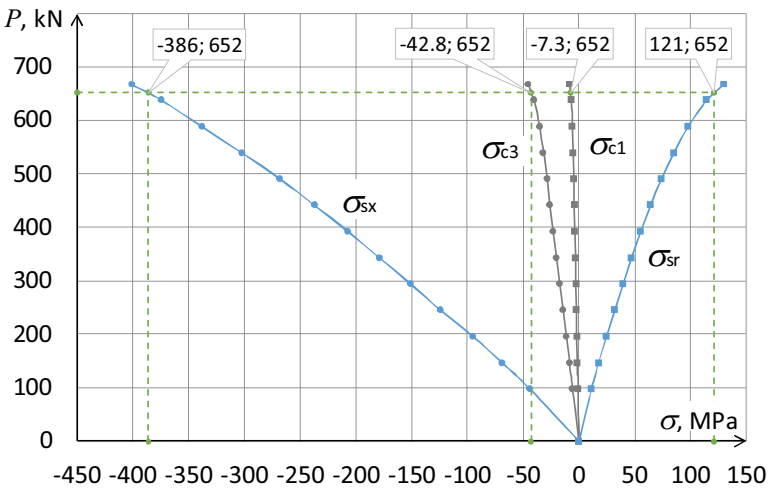

a)

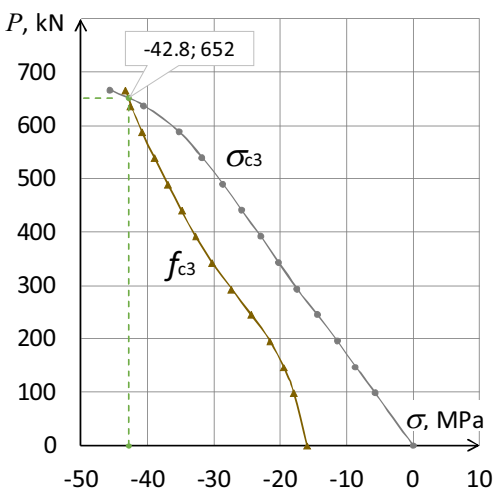

b)

Fig. 3. Diagrams of stress change in the concrete pipe element ( $a$ - stress diagrams, $b$ - core strength diagram $f_{\mathrm{c} 3}$ together with stress diagram in the concrete $\left.\sigma_{\mathrm{c} 3}\right)$.

The core strength diagram $f_{\mathrm{c} 3}$ (Fig. $3, \mathrm{~b}$ ) has the common solution with the axial stress development curve in the concrete $\sigma_{\mathrm{c} 3}$, which determines the strength criterion of the stress state $\left(N_{\text {plf }}=652 \mathrm{kN}\right)$. Load-carrying capacity of the concrete pipe element was obtained based on the value of limit relative concrete deformations $\varepsilon_{\mathrm{cu}}\left(N_{p l \varepsilon}=648 \mathrm{kN}\right)$. 
Analysis of the diagrams demonstrates approximately similar type of dependencies of deformation changes in the core and in the confinement that indicates their joint performance.

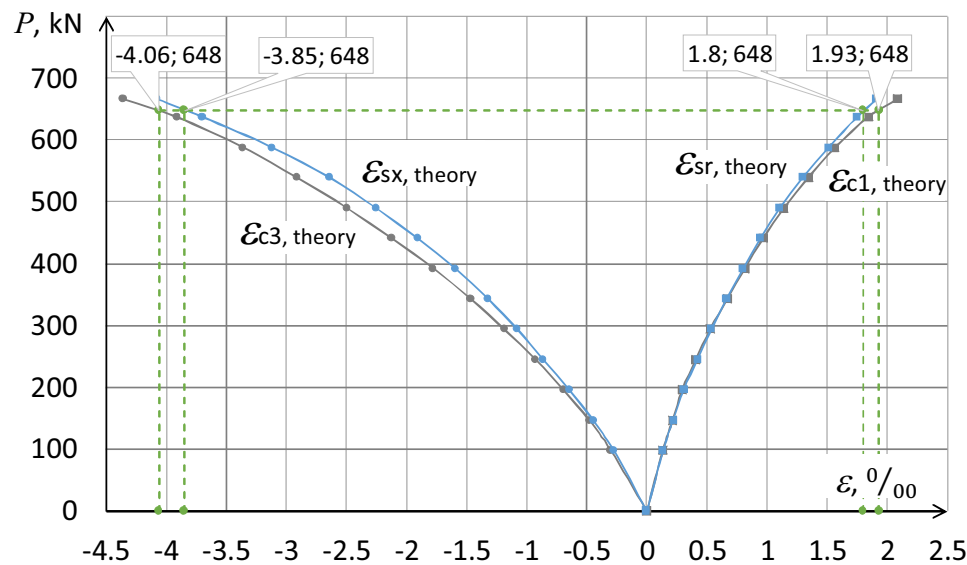

Fig. 4. Diagrams of deformation change in the concrete pipe element.

The factor of numerical adjustment of the effect of the confinement is determined by the relation of the core strengths in the limit and initial state. For the reference relation $D / t=34$, strength of the concrete core increase 2.6 times.

Test specimens for experimental studies were concreted in the laboratory of the Department of structural mechanics of the Ukrainian State University of Railway Transport (Fig. 5). Fine grain concrete c $\mathrm{W} / \mathrm{C}=0.55$, portlandcement $\mathrm{M} 500$ and broken stones of 2.5-7 mm fraction were used to prepare the concrete mixture. Deformations in the concrete were measured in the geometric centre of the core using low-depth strain gauge load cells [5]. Deformations of the confinement were measured on the surface in the middle of the element length. The mean error obtained for relative deformations in the core and the confinement was found to be $10.5 \%$. In general, the error for the load-carrying capacity is not more than $2.5 \%$.
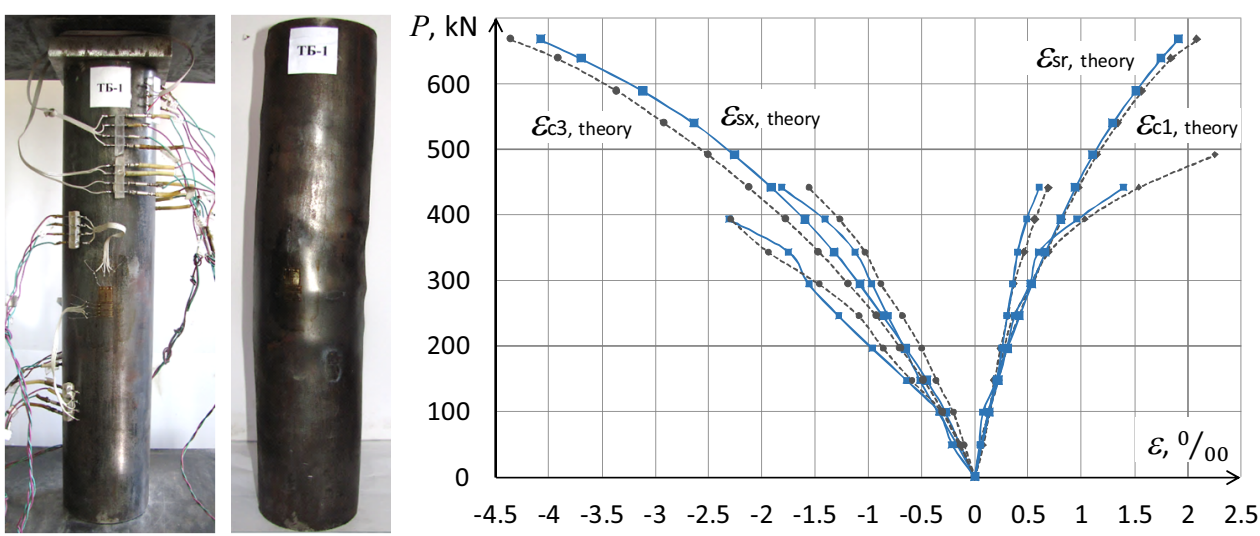

Fig. 5. Experimental data.

Assuming satisfactory convergence of theoretical and experimental data for short-term loads, the next step considers the influence of the time factor on deformation in the concrete core and, in general, on the stress-strain state of the concrete pipe element. 


\section{Calculation for short-term loads}

\subsection{Theoretical principles}

Numerous experimental studies have demonstrated that inelastic deformations occur in constructions in which concrete is used exposed to long-term load action, which can exceed several times the initial, conditionally elastic deformations. The issue of creep is critical for the structures made of steel-reinforced concrete and in particular, for concrete slabs $[6,7]$ and pipe concrete. Therefore, the issues of forecasting the long-term deformation of the concrete core in concrete pipe elements and synchronous redistribution of efforts remain relevant.

The national building codes of Ukraine harmonized with Eurocode 2 [8] are based on the simplest - phenomenological - approach which, in turn, is based on experimental data and establishing dependency between deformations and time through the creep coefficient $\varphi\left(t, t_{0}\right)$. In accordance with this method, the ultimate creep deformations are determined by a coefficient that depends on the average strength of the concrete, its age and relative humidity, while the development of creep in time $t$ depends on relative humidity and crosssection.

$$
\varepsilon_{\mathrm{c}, \mathrm{t}}=\sigma_{\mathrm{c}} / E_{\mathrm{c}}\left[1+\varphi_{0} \beta\left(t, t_{0}\right)\right],
$$

where: $\beta\left(t, t_{0}\right)$ - coefficient describing the development of creep over time; $t_{0}$-age of the concrete at the time of the first load.

Despite its advantages, this method cannot reveal the actual mechanism of long-term deformation of the concrete, and thus does not allow to control this mechanism and influence the ultimate values of creep deformations. Since alternative methods of creep accounting can be applied using special software, we propose a method based on the colloidal chemical representation of the mechanism of long-term deformation of concrete in accordance with the Plugin theory [9].

The theory is based on the more accurate representation of the kinetic curve of concrete deformation (Fig. 6). Based on the findings of the study, the equations of deformation development were obtained depending on 4 stages of concrete performance: compression in the conditionally elastic setting, the stage of high-rate creep (1), ordinary creep, consisting of a nonlinear (2) and a linear (3) part, as well as long-term creep (4). The data are confirmed by experimental studies with continuous loading of $10 \times 10 \times 40 \mathrm{~cm}$ cement prisms.

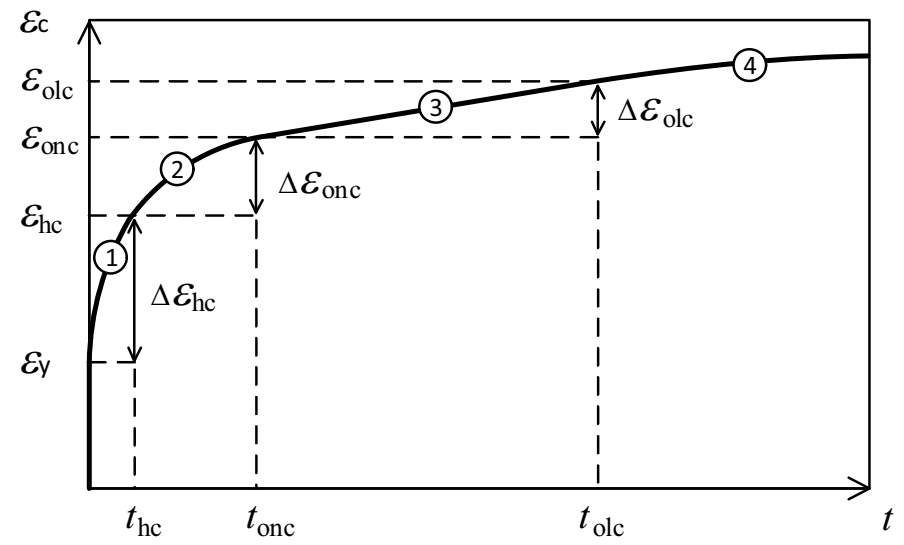

Fig. 6. Generalized kinetic nomogram of creep of concrete. 
In accordance with Fig. 1, the pattern of the long-term deformation of the concrete under compression and the general concrete deformation equation becomes the form:

$$
\varepsilon_{\mathrm{c}}=\varepsilon_{\mathrm{y}}+\Delta \varepsilon_{\mathrm{hc}}+\Delta \varepsilon_{\mathrm{onc}}+\Delta \varepsilon_{\mathrm{olc}}+\Delta \varepsilon_{\mathrm{lc}} .
$$

Specific equations simulating deformation kinetics at each of the above stages:

$$
\begin{gathered}
\varepsilon_{\mathrm{c}, \mathrm{hc}}(t)=\varepsilon_{\mathrm{y}}+\Delta \varepsilon_{\mathrm{hc}}\left(1-e^{-t / T_{\mathrm{r}}^{\mathrm{hc}}}\right), \\
\varepsilon_{\mathrm{c}, \mathrm{onc}}(t)=\varepsilon_{\mathrm{hc}}+\Delta \varepsilon_{\mathrm{onc}}\left(1-e^{-t / T_{\mathrm{r}}^{\mathrm{onc}}}\right), \\
\varepsilon_{\mathrm{c}, \mathrm{olc}}(t)=\varepsilon_{\mathrm{onc}}+k_{\mathrm{olc}}\left(t-t_{\mathrm{onc}}\right), \\
\varepsilon_{\mathrm{c}, \mathrm{lc}}(\mathrm{t})=\varepsilon_{\mathrm{olc}}+k_{\mathrm{l}}\left(t-t_{\mathrm{olc}}\right),
\end{gathered}
$$

where: $T_{\mathrm{r}}^{\mathrm{hc}}, T_{\mathrm{r}}^{\mathrm{onc}}$ - relaxation time according to the Tertsagi's dispersion phase model on the exponential deformation stages;

$k_{\text {olc }}, k_{1}-$ kinetic coefficients reflecting rate of general (on the linear section) and long-term creep deformation.

In view of the latter, expression for determination of the creep coefficient at any concrete deformation stage becomes the form:

$$
\varphi(t)=\left[\varepsilon_{\mathrm{c}}(t)-\varepsilon_{\mathrm{c}, \mathrm{y}}\right] / \varepsilon_{\mathrm{c}, \mathrm{y}}
$$

Total relative concrete deformations, corresponding to completion of the high-rate $\left(\varepsilon_{\mathrm{hc}}\right)$ and ordinary $\left(\varepsilon_{\text {onc }}, \varepsilon_{\text {olc }}\right)$ creep stage, are determined based on the hypothesis about the behaviour mechanism of submicroscopic structure of the concrete consisting of electrically charged particles (globules) of hydrosilicate gel when it is exposed to compressing load. It is assumed that ultimate creep deformations are determined by gel deformations due to compression of double electric layer, water filtration from the compressed areas of the construction into those stretched according to the pressureless water penetration law, while long-term creep kinetics will depend on the scale factor during filtration water squeezing from the gel.

Creep deformations can be controlled through new structural coefficients determining the structure of cement stone layers between the sand and mortar grains between chip grains [9]:

$$
\begin{array}{r}
\alpha=V_{\mathrm{csm}} / V_{\mathrm{emp}}^{\mathrm{bs}}=\left(\frac{\mathrm{s}}{\rho^{\mathrm{s}}}+\frac{\mathrm{C}}{\rho^{\mathrm{C}}}+\frac{\mathrm{W}}{\rho^{\mathrm{W}}}\right) /\left(\frac{\mathrm{BS}}{\rho_{\text {pour }}^{\mathrm{bs}}} \cdot \mathrm{S}_{\mathrm{emp}}^{\mathrm{bs}}\right) ; \\
\mu=V_{\mathrm{cs}} / V_{\mathrm{emp}}^{\mathrm{s}}=\left(\frac{\mathrm{C}}{\rho^{\mathrm{C}}}+\frac{\mathrm{W}}{\rho^{\mathrm{W}}}\right) /\left(\frac{\mathrm{s}}{\rho_{\text {pour }}^{\mathrm{S}}} \cdot \mathrm{S}_{\mathrm{emp}}^{\mathrm{bs}}\right) .
\end{array}
$$

The best coefficients $\alpha_{\text {opt }}$ and $\mu_{\text {opt }}$ were obtained from the condition of the fullest contact which decreases disjoining pressure and, respectively, compressive deformations and hair cracks.

A calculation algorithm for the long-term load action was suggested (Fig. 7), which in combination with Lira-SAPR software allows to perform adjusted calculation of constructions for long-term exposure and control creep deformations through the structural characteristics $\alpha$ and $\mu$.

PCC - specialized software developed at the Department of building materials, constructions and structures of the Ukrainian State University of Railway Transport - is used to determine dosing of concrete components according to the specified data. 


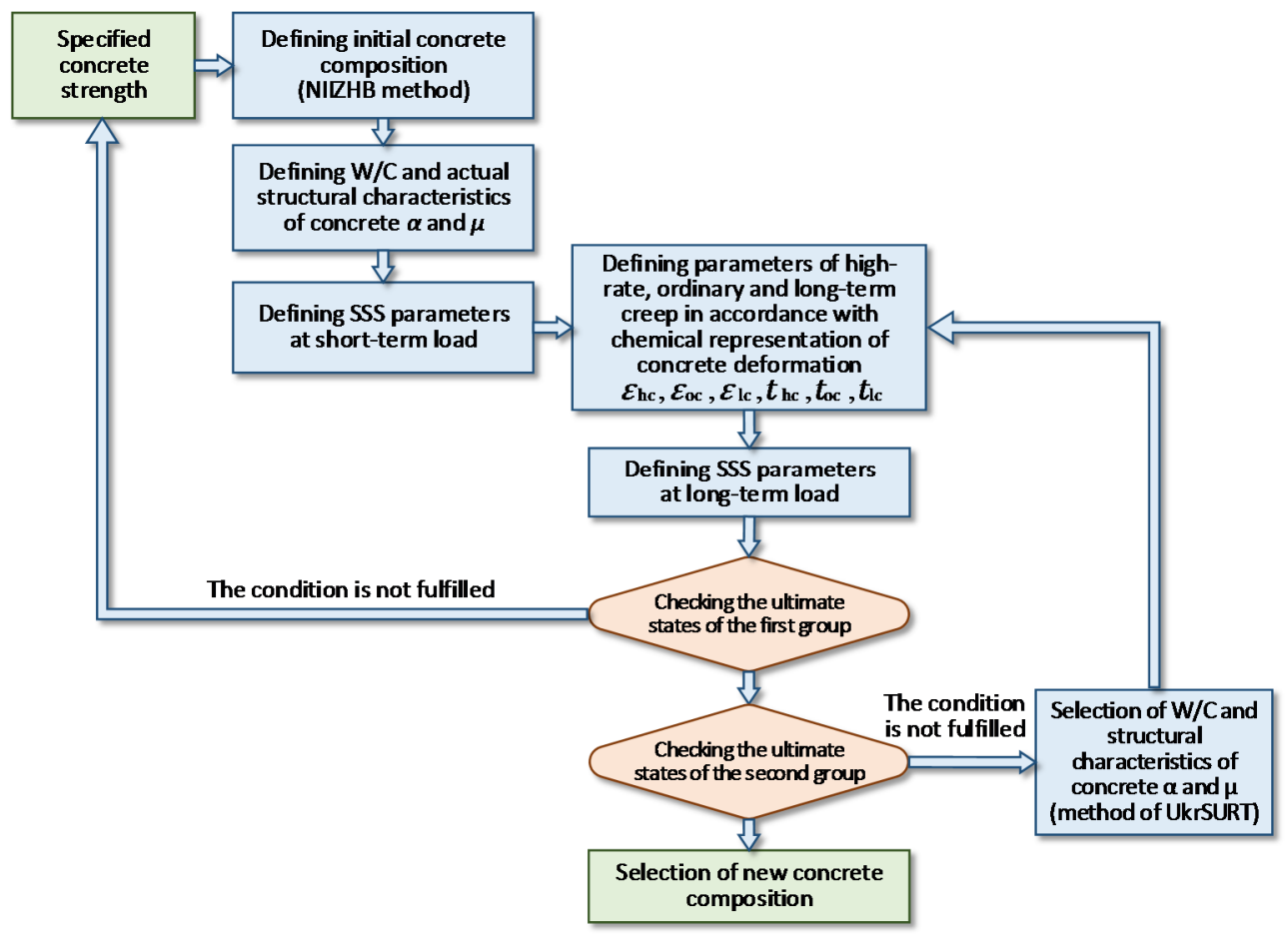

Fig. 7. Algorithm of minimization of limit creep deformations.

\subsection{Calculation data}

For the considered pipe concrete elements, calculation taking into account long-term load exposure determined significant stress redistribution towards the confinement (Fig. 8). For instance, in 730 days under stress of $50 \%$ of the carrying capacity, axial $\sigma_{\mathrm{sx}}$ and transverse $\sigma_{\mathrm{sr}}$ stresses in the confinement increase by $60 \%$ and $70 \%$, respectively. Axial stresses in the core $\sigma_{\mathrm{c} 3}$ decrease by $40 \%$, while transverse stresses and $\sigma_{\mathrm{c} 1}$, on the contrary, increase by $50 \%$. Strength of the concrete core $f_{\mathrm{c} 3}$, during the long-term loading, increases additionally by $20 \%$. Axial deformations in the core $\varepsilon_{\mathrm{c} 3}$ increase by $70 \%$.

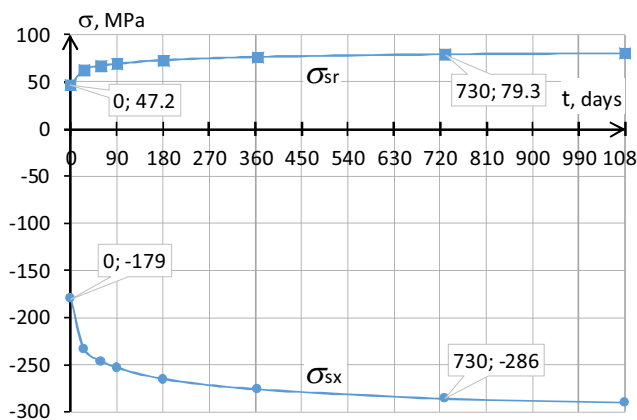

a)

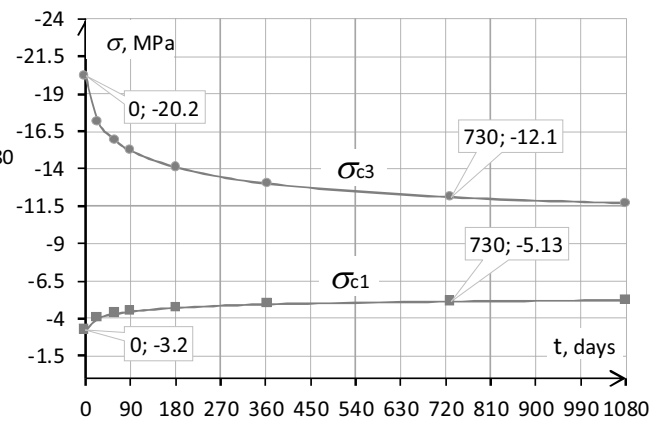

b)

Fig. 8. Diagrams of stress changes in a pipe concrete element $\left(\mathrm{a}-\right.$ stress changes $\sigma_{\mathrm{sx}}$ and $\sigma_{\mathrm{sr}}$ in the confinement, $\mathrm{b}$ - stress changes $\sigma_{\mathrm{c} 3}$ and $\sigma_{\mathrm{c} 1}$ in the core).

The performed studies resulted in obtaining a method for calculating the stress-strain state and bearing capacity of pipe concrete elements taking into account the short-term and 
long-term load action, physical nonlinearity of materials, geometric nonlinearity of the confinement, compressing effects of concrete, and increase of the strength of the core. Validity of the method is provided by comparing experimental and theoretical results.

The adopted long-term load accounting method includes an algorithm for creep controlling through the structural characteristics of concrete. It is also established that the long-term processes that occur in the concrete core affect significantly the stress-strain state. The performance of pipe concrete does not decrease with time and will depend on the reasonable concrete composition and the optimal proportions of design parameters.

\section{References}

1. L.I. Storozhenko, A.V. Semko, Urban economy, Kharkiv, 63, 59-70 (2005)

2. Design of composite steel and concrete structures - Part 1-1: General Rules and Rules for Bridges. EN 1994-1: 2001. Eurocode 4, Brussels (2006)

3. A.S. Gorodetsky, Computer models of structures (Fact, Kyiv, 2007)

4. N.I. Karpenko, General models of reinforce concrete mechanics (Stojizdat, Moscow, 1996)

5. G.L. Vatulia, E.I. Galaguria, D.G. Petrenko, Transport, Transport Facilities and Ecology, Perm, 2, 48-56 (2014)

6. A.V. Lobiak, D.V. Golovko, Steel concrete structures: design, construction and maintenance, Poltava, 11, 156-162 (2014)

7. A.V. Lobiak, A.A. Plugin, D.V. Golovko, News of ODABA, Odesa, 63, 79-83 (2016)

8. Design of Concrete Structures- Part 1-1: General Rules and Rules for buildings EN 1992-1-1. Eurocode 2, Brussels (2004)

9. A.N. Plugin, A.A. Plugin, O.A. Kalinin et al. Osnovy teorii tverdeniya, prochnosti, razrusheniya $i$ dolgovechnosti portlandtsementa, betona $i$ konstruktsiy iz nikh (Naukova dumka, Kyiv, 2012) 